\title{
O TRABALHO COMO ESTRATÉGIA DE REINSERÇÃO PSICOSSOCIAL DO DEPENDENTE QUÍMICO SOB A ÓTICA DA FAMÍLIA
}

\author{
| Elias Barbosa de Oliveira ${ }^{1}$; Michele Borges dos Santos²; Olivia de Andrade Guerra ${ }^{3}$ |
}

\section{RESUMO}

CONTEXTO: O estigma da dependência química e as recaídas são fatores que dificultam a inserção do indivíduo no mercado de trabalho. OBJETIVO: Analisar o entendimento da família acerca do trabalho como estratégia de reinserção psicossocial do dependente químico.

MÉTODO: Estudo qualitativo descritivo. Utilizou-se a entrevista semiestruturada mediante um roteiro e no tratamento dos dados a análise de conteúdo. Participaram do estudo 10 famílias de uma unidade de internação psiquiátrica de um hospital universitário público situado no município do Rio de Janeiro (Brasil), em 2015.

RESULTADOS: Na visão da família o trabalho é uma estratégia eficaz de reinserção psicossocial do dependente químico, pois através dele a pessoa exerce a sua criatividade e autonomia. No entanto a recaída afeta o desempenho devido a faltas, atrasos e conflitos no trabalho, culminando com o desemprego e as sobrecargas financeira, emocional e social da família. A pouca autonomia do dependente químico e os gastos com drogas propiciam um ambiente de conflitos e tensões no ambiente familiar e a codependência.

CONCLUSÔES: As recaídas do dependente químico e as dificuldades de inserção no trabalho acarretam sobrecarga emocional, social e financeira a família, exigindo ações de cunho preventivo e terapêutico junto ao grupo por parte dos serviços de saúde mental.

\section{PALAVRAS-CHAVE: Relações familiares; Bebidas alcoólicas; Saúde mental; Saúde do trabalhador}

\section{RESUMEN}

"El trabajo como estrategia de reinserción psicosocial del dependiente químico bajo la óptica de la familia“

CONTEXTO: El estigma de la dependencia química y las recaídas son factores que dificultan la inserción del individuo en el mercado de trabajo. OBJETIVO: Analizar el entendimiento de la familia acerca del trabajo como estrategia de reinserción psicosocial del dependiente químico.

MÉTODO: Estudio cualitativo descriptivo. Se utilizó la entrevista semiestructurada mediante un guión y en el tratamiento de los datos el análisis de contenido. Participaron del estudio 10 familias de una unidad de internación psiquiátrica de un hospital universitario público situado en el municipio de Río de Janeiro (Brazil), en 2015.

RESULTADOS: En la visión de la familia el trabajo es una estrategia eficaz de reinserción psicosocial del dependiente químico, pues a través de él la persona ejerce su creatividad y autonomía. Sin embargo la recaída afecta el desempeño debido a las faltas, retrasos y conflictos en el trabajo, culminando con el desempleo y las sobrecargas financiera, emocional y social de la familia. La poca autonomía del dependiente químico y los gastos con drogas propician un ambiente de conflictos y tensiones en el ambiente familiar acarreando la codependencia de la familia.

CONCLUSIONES: Las recaídas del dependiente químico y las dificultades de inserción en el trabajo acarrean sobrecargas emocional, social y financiera a la familia, exigiendo acciones de carácter preventivo y terapéutico junto al grupo por parte de los servicios de salud mental.

\section{DESCRIPTORES: Relaciones familiares; Bebidas alcohólicas;} Salud mental; Salud del trabajador

\begin{abstract}
"Work as a strategy of psychosocial reinsertion of the dependent chemist from the perspective of the family"

BACKGROUND: The stigma of chemical dependence and relapses are factors that hinder the insertion of the individual in the labor market. AIM: To analyze the family's understanding of work as a strategy of psychosocial reinsertion of the chemical dependent.

METHOD: Descriptive qualitative study. The semi-structured interview was used through a script and in the data treatment the content analysis. Ten families from a psychiatric inpatient unit of a public university hospital located in the city of Rio de Janeiro (Brazil), in 2015, participated in the study.

RESULTS: In the family view, work is an effective strategy for the psychosocial reinsertion of the chemical dependent, because through him the person exercises his creativity and autonomy. However, relapse affects performance due to absences, delays and conflicts at work, culminating in unemployment, and financial, emotional and social overload of the family. The low autonomy of the chemical dependents and drug spending provide an environment of conflicts and tensions in the family environment, causing the codependency of the family.

CONCLUSIONS: The relapses of the chemical dependents and the difficulties of insertion in the work lead to emotional, social and financial overload on the family, requiring preventive and therapeutic actions with the group by the mental health services.
\end{abstract}

\section{KEYWORDS: Family relations; Alcoholic beverage; Mental health; Worker's health}

Submetido em 30-09-2018

Aceite em $05-12-2018$

\footnotetext{
1 Professor Associado de Enfermagem em Saúde Mental e Psiquiatria na Universidade do Estado do Rio de Janeiro, Faculdade de Enfermagem, Departamento de Enfermagem Médico Cirúrgico, Boulevard 28 de Setembro, 157, 20551-030 Vila Isabel (RJ), Brasil, eliasbo@oi.com.br

2 Enfermeira especialista em Enfermagem Psiquiátrica e Saúde Mental no Hospital Municipal Rocha Faria (SMS), Campo Grande (RJ), Brasil, miicheleborges@gmail.com 3 Enfermeira; Mestre em Enfermagem; Especialista em Enfermagem Psiquiátrica e Saúde Mental na Secretaria Municipal de Saúde do Rio de Janeiro, Centro de Atenção Psicossocial Álcool de Drogas Antônio Carlos Mussum, 22713-560 Jacarepaguá (RJ), Brasil, oliviaaguerra@gmail.com
} 


\section{INTRODUÇÃO}

O texto da reforma psiquiátrica no Brasil ratificou, de forma histórica, as diretrizes básicas que garantem aos indivíduos que sofrem de transtorno mental e daquele decorrente do consumo de álcool e outras drogas a desinstitucionalização e a universalidade de acesso e direito à assistência. Tais diretrizes devem ser executadas através da ampliação da rede ambulatorial e o fortalecimento de iniciativas que propiciem a Rede de Atenção Psicossocial (RAPS) com a criação de equipamentos intensivos e intermediários entre o tratamento ambulatorial e a internação hospitalar, com ênfase nas ações de reabilitação psicossocial dos pacientes (Amarante, 2013).

Em um contexto de mudanças econômicas, políticas e sociais, a reforma psiquiátrica surgiu como um movimento que tem entre seus propósitos a desinstitucionalização e a reabilitação psicossocial; entendida como um conjunto de ações que visam aumentar as habilidades da pessoa, diminuindo o dano causado pelo transtorno mental, as longas internações e envolvendo todos aqueles que fazem parte do processo saúde-doença, ou seja, usuários, familiares, profissionais e comunidade em geral. Consiste, portanto, em um processo de reconstrução da cidadania do sujeito, devendo contemplar os três vértices da vida humana: casa, lazer e trabalho (Saraceno, 2001).

A reforma abriu o caminho para outras inciativas e/ ou políticas publicas em saúde mental como a Política Nacional Especifica para Álcool e Drogas, que assume o desafio de prevenir, tratar e reabilitar os usuários na amplitude de seu contexto social. Ao se prover a saúde pode-se reduzir o consumo e o abuso das drogas na realidade social, uma vez que promover a saúde é uma atitude que está de acordo com o modelo vigente de inclusão do sujeito em seu território. Portanto, o indivíduo com diagnóstico de dependência química deve receber tratamento em serviços especializados como os centros de atenção psicossocial álcool e drogas (CAPSad), com profissionais capacitados para o efetivo atendimento e participação da família (Ministério da Saúde, 2011).

Assevera-se que a partir da legitimação do acesso universal à prevenção e tratamento da dependência química no país e, tendo em vista as inúmeras implicações decorrentes do consumo abusivo de álcool e outras drogas para o indivíduo e sociedade (Lima, Breda, \& Albuquerque, 2013), há urgência de estratégias que deem suporte às famílias em sofrimento psíquico.
As ações devem produzir acolhimento, diante das sobrecargas sofridas em seu dia a dia com os problemas decorrentes da dependência química. Portanto, as ações dirigidas ao grupo devem contemplar a perspectiva de rede de cuidados em saúde mental para a efetividade de terapêuticas e prevenção de recaídas.

Uma das inciativas que tem contribuído para a reabilitação do indivíduo em sofrimento mental ou com problemas decorrentes do uso abusivo de álcool e drogas é a inclusão social pelo trabalho, que emergiu da parceria firmada entre a Secretaria Nacional de Economia Solidária do Ministério do Trabalho e Emprego com a Coordenação Nacional de Saúde Mental (MS). O Grupo de Trabalho tem como proposta a reabilitação psicossocial e econômica do individuo, através da inserção em oficinas de produção de trabalho e renda organizadas coletivamente. A economia solidaria baseia-se na construção de relações que oportunizam a reabilitação psicossocial e econômica de pessoas que estão à margem da sociedade, propiciando deste modo à inclusão social e maior autonomia, inclusive em relação à família (Amarante, 2013).

A pessoa com transtorno mental segundo Volz et al, (2015) sofre com o estigma da doença e/ou identidade desacreditada, pois a discriminação causa outros danos como baixa autoestima, interferindo na confiança como cidadão e na qualidade de vida. Portanto, a inclusão social pelo trabalho exerce papel de suma importância no processo de redução do estigma social. Nesse sentido as cooperativas sociais e as oficinas de geração de trabalho e renda, propiciam um ambiente de troca de experiências e vivências, possibilitando aos sujeitos que compartilham da mesma problemática, construir conjuntamente um processo de autoafirmação e de redes sociais. Ao conceberem o grupo como uma "família" essas pessoas têm os sentimentos de medo e desvalorização visivelmente minimizados.

Tendo em vista as mudanças ocorridas com a reforma psiquiátrica no país no que diz respeito à inclusão da família no tratamento, (Amaral \& Bressen, 2015) os profissionais precisam estimular o protagonismo e o empoderamento dessas famílias com o intuito de superação de suas dificuldades e fragilidades, de modo que essas se percebam como parte do processo orientado pelos profissionais. O êxito das ações depende da postura adotada e da condução do trabalho, instigando a participação dos familiares e pacientes nas decisões, considerando o respeito às formas de organização das famílias, suas crenças, valores e cultura e os respectivos contextos em que se encontram. 
O objetivo do estudo foi analisar o entendimento da família acerca do trabalho como estratégia de reinserção psicossocial do dependente químico.

\section{METODOLOGIA}

Trata-se de um estudo de caráter descritivo com abordagem qualitativa (Minayo, 2013) que buscou compreender um problema na perspectiva dos sujeitos que o vivenciam, partindo de suas vidas diárias, satisfações, desapontamentos, surpresas e outras emoções. O projeto foi aprovado pelo Comitê de Ética em Pesquisa (CEP/HUPE) e protocolado no Comitê Nacional de Ética em Pesquisa (CAAE - 42605315.9.0000.5259) e parecer de número 999.078.

O campo foi uma unidade de internação psiquiátrica de um hospital universitário situado no município do Rio de Janeiro. Esta unidade integra a Rede de Atenção Psicossocial (RAPS) do município e destinada ao tratamento de um pequeno número de pacientes com transtornos mentais e dependentes químicos; cujo modelo de atendimento é a Comunidade Terapêutica. Como não possui serviço de emergência, os leitos são ocupados por pacientes matriciados pelos serviços substitutivos em saúde mental do Sistema Único de Saúde (SUS). O tempo de internação é breve, em torno de 15 dias, e $o$ atendimento realizado por equipes multiprofissionais de saúde mental. A planta física é horizontal com seis casas geminadas, sendo cada casa composta por um quarto com dois leitos e um banheiro. A unidade possui também um posto de enfermagem, um refeitório, uma copa, um pequeno anfiteatro e salas destinadas à parte administrativa.

Em atendimento à Resolução 466/12, após a assinatura do Termo de Consentimento Livre e Esclarecido, participaram do estudo 10 familiares a partir dos seguintes critérios de inclusão: maior de dezoito anos, conviver no mesmo espaço domiciliar que o paciente, participar direta ou indiretamente do tratamento, não ter transtorno mental ou outro tipo de problema de saude que interferisse na qualidade dos depoimentos e se disponibilizar a participar do estudo. Excluídos os familiares menores de dezoito anos, aqueles que não convivessem sob o mesmo teto do paciente, que tivessem problemas de saude de qualquer natureza e que não concordassem em participar do estudo.

Informou-se que a participação dos entrevistados seria voluntária e que teriam o direito de se retirar da pesquisa em qualquer fase, sem que isso trouxesse qualquer dano ou retaliação.
Garantiu-se o sigilo dos dados e ratificou-se que os resultados seriam apresentados em eventos científicos e publicados em revistas científicas. Na transcrição dos depoimentos foram adotadas as seguintes convenções: entrevistado (letra E) seguido de um número de acordo com a ordem de entrada no texto.

As entrevistas foram coletadas no período de abril a junho de 2015, na própria unidade em local livre de interferências após agendamento e disponibilidade dos familiares, sendo gravadas em meio digital (gravador Mp3) e durado em torno de 40 minutos. Optou-se pela técnica de entrevista semiestruturada mediante um roteiro com questões abertas que contribuíram para esclarecer a problemática da investigação. $\mathrm{Na}$ realização das entrevistas, foi utilizado um roteiro contendo cinco questões abertas sobre o objeto de estudo de modo que os familiares falassem a respeito da problemática, sem nenhum tipo de interferência ou indução as respostas. Realizada a transcrição dos depoimentos na integra, sendo o corpus do texto analisado mediante a técnica de análise de conteúdo do tipo temática (Bardin, 2011), que consistiu em um conjunto de técnicas de análise das comunicações, visando obter por procedimentos sistemáticos e objetivos de descrição do conteúdo das mensagens, indicadores (quantitativos ou não) que permitiram a inferência de conhecimentos relativos às condições de produção/recepção (variáveis inferidas) destas mensagens. Em um último momento, utilizando os critérios de representatividade, homogeneidade, reclassificação e agregação dos elementos do conjunto, foram elaboradas as seguintes categorias: a difícil inserção psicossocial do dependente químico pelo trabalho devido a recaídas; sobrecarga financeira da família e conflitos; sofrimento e codependência da família; quando ainda há esperança: reinserção psicossocial através do trabalho.

\section{RESULTADOS}

\section{A Difícil Inserção Psicossocial do Dependente Químico pelo Trabalho Devido a Recaídas}

Evidenciado no estudo que a reinserção psicossocial do dependente químico através do trabalho, em algumas circunstâncias é prejudicada, pelo fato de o consumo afetar o desempenho e demais atividades do dia a dia como lazer, trabalho e outras. Não se elimina a possibilidade de recaída, e/ou encontrar-se na fase de contemplação por achar que possui controle sobre o consumo da droga. 
Como referido pela família, o consumo de substancias psicoativas pelo indivíduo é denunciado em função de atitudes e/ou comportamentos que vão de encontro às normas estabelecidas no ambiente laboral devido a problemas como: faltas, quedas, embriaguez e até mesmo agressões contra os colegas.

Ela foi demitida porque chegou alcoolizada e faltava muito (F6)

Ela perdeu o último emprego por chegar ao trabalho drogada! Escorregou e caiu e o patrão viu (F7).

Foi mandado embora porque chegou embriagado e agrediu um colega (F10).

\section{Sobrecarga Financeira da Família e Conflitos}

Identificou-se que a família se sente sobrecarregada financeiramente pelo fato de o dependente químico não contribuir com as despesas e, apesar de em algumas situações os familiares relatarem que o ente possui renda própria, os recursos financeiros advindos do trabalho não entram como parte da renda familiar, sendo consumidos com as drogas. Deste modo a família se ressente por ter que arcar com as despesas e as decorrentes do consumo de drogas; fatores que propiciam a quebra da confiança e desestabilizam o relacionamento no grupo.

Ele não contribui com as despesas da casa. A gente não sabe pra onde vai o dinheiro dele (F2).

Financeiramente eu tenho as rédeas! Estou me sobrecarregando (F3).

Me prejudicou muito financeiramente porque tive que pegar empréstimo pra montar uma casa (F6).

Quem segura o cartão do pagamento sou eu! O problema que eu tive foi de pagar as contas de bebida no bar! Quase mil reais de bebida (F4).

\section{Sofrimento e Codependência da Família}

Os relatos retratam os impactos emocionais e sociais que a dependência química acarreta aos familiares, em que se evidenciam sentimentos de impotência, tristeza, revolta e decepção em função das sucessivas recaídas por parte do familiar. Além do sofrimento psíquico identificou-se o agravamento de conflitos familiares existentes, contribuindo para a codependência familiar e as dificuldades em acolher o sofrimento do próprio dependente químico.

Nós já estamos afetados há muitos anos por causa do uso de drogas! Emocionalmente eu morro de vergonha no meu trabalho e na vizinhança. Eu chorava muito! Foi muito difícil pra mim (F2).
Minha pressão sobe e já tive paralisia facial (F3).

Toda família ficou afetada! Todo mundo tinha expectativa nela em alguma coisa. Isso que foi dando minha depressão (F4).

O filho dela ficou muito revoltado! Tentou suicídio. (F6).

\section{Quando Ainda Há Esperança: Reinserção Psicosso- cial através do Trabalho}

Apesar das dificuldades enfrentadas pela família no que diz respeito à reinserção psicossocial do dependente químico através do trabalho, principalmente na ocorrência de recaídas, houve relatos dos aspectos positivos que o trabalho propicia por contribuir com a organização das atividades cotidianas, a maior autonomia e a credibilidade frente a família. Há também os ganhos advindos do trabalho na medida em que a pessoa se mostra produtiva, exerce as suas potencialidades. Por outro lado, persiste a visão equivocada por parte dos familiares do trabalho como mera distração, desprovido de seu potencial terapêutico e psicossocial.

Ele respeita o horário do serviço e não bebe (F2).

Ele produz! E é inteligente! Criativo! Os anúncios (referindo-se ao trabalho de diagramador) têm conteúdo. Ele trabalha em casa (F3).

Em algum momento ele vai ter que voltar a trabalhar, porque, lógico que contribui pra recuperação dele (F5). $\mathrm{O}$ trabalho ajuda porque tem sido forma de distração (F9).

\section{DISCUSSÃO}

O consumo de substâncias psicoativas por trabalhadores na acepção de Félix Junior et al, 2014 ainda é uma problemática pouco valorizada por empresas e instituições, tendo como consequência o medo do desemprego por parte do trabalhador. O consumo contribui para a redução da produtividade, aumento dos acidentes de trabalho e riscos para a vida do indivíduo e de outras pessoas. Há uma tendência por parte do empregador em culpar o trabalhador pelo uso de drogas, não tomando para si o problema e nem encaminhando para o tratamento. Pode ser que o empregado se veja culpado e assim se torne o único responsável pela sua recuperação. Pesquisas apontam que o trabalho em si não é o maior motivador para o consumo de substâncias psicoativas, mas as chances de consumo aumentam quando as condições laborais são desgastantes, estressantes e desmotivadoras para o trabalhador. 
Portanto, há necessidade de suporte ao trabalhador com histórico de consumo de substancias psicoativas por parte das instituições empregadoras (Bessa \& Pagliarini, 2013) diante dos riscos para a saúde e o desempenho. $\mathrm{O}$ afastamento pode ser necessário até que cessem os sintomas do consumo de drogas, sendo essencial garantir os direitos trabalhistas e a proteção social. Afinal a recaída leva ao consumo _ independente do vínculo empregatício e consequentemente a diminuição da capacidade e do rendimento laboral. Pensar a reinserção psicossocial do dependente sob o olhar da família (Salles \& Barros, 2017) é também entender as dificuldades enfrentadas pelo grupo na sua inclusão social, como também o preconceito e a discriminação quando estas pessoas tentam participar de atividades de lazer em ambientes comunitários. Os centros de atenção psicossocial no país vêm ajudando a preencher este vazio, mas não tem sido efetivo no que diz respeito ao acolhimento por parte da comunidade, sendo indicativo da necessidade de expansão das atividades sociais para fora das instituições.

Nas novas composições familiares (Amaral \& Bressan, 2015), a família é entendida como uma instituição composta por pessoas ligadas por laços afetivos, consanguíneos e de afinidade. Possui a função de socialização, cuidado, proteção e sobrevivência de seus membros, mas também se caracteriza como um espaço de disputa e de conflitos entre seus entes. Portanto, o trabalho com famílias exige preparo profissional e conhecimentos, devendo-se ter o cuidado de não responsabilizar os familiares por recaídas e/ou insucesso do tratamento, pois nenhuma família encontra-se preparada para ter um membro doente; daí a importância de suporte ao grupo por parte dos profissionais.

$\mathrm{O}$ depende químico no contexto social e familiar que não se apresenta produtivo em função das recaídas (Schein \& Boeckel, 2012) tem diminuída a sua autonomia frente a família e sociedade, passando a sua vida e demais questões de fórum privado a ser controlada pela família. Devem-se considerar as limitações do dependente quanto à responsabilidade e o controle financeiro devido à própria dificuldade de administrar seus bens. Há uma preocupação das famílias com o futuro do ente adoecido em termos de inserção social, suporte financeiro (benefício ou aposentadoria) e de apoio social (ter alguém para amparar e cuidar).

Neste sentido como nos mostram Bessa \& Pagliarini (2013), apesar de algumas famílias que possuem em seu núcleo pessoas com transtorno mental receberem auxilio do governo através do Programa "De Volta para Casa”, nem sempre este beneficio atende a demandas decorrentes da compra de medicamentos, reposição de material domiciliar (devidos a perdas em momentos de crise e agressividade). Há também as dificuldades de inserção da pessoa com transtorno mental no mercado de trabalho ou manutenção do emprego quando se encontra com a sintomatologia e em descontrole do tratamento. Diante da sobrecarga sofrida, a família pode assumir formas de enfrentamento singulares (Kalan et al, 2017), oscilando desde ações de vigilância, estabelecimento de limites, supervisão do autocuidado e até mesmo posturas apáticas em função do sofrimento gerado pelas demandas do familiar adoecido. Portanto, torna-se imprescindível facilitar a continuidade do apoio multidisciplinar oferecido aos familiares, como também manutenção de espaços de trocas cotidianas, momento em que essas pessoas falam dos seus problemas e anseios, aliviando deste modo a carga emocional e tornando-se mais aptas a lidar com o adoecimento do familiar. Deste modo, o cotidiano das famílias (Bessa \& Pagliarini, 2013) é modificado com o advento da doença, que provoca alterações das atividades cotidianas como lazer, trabalho e convívio social. Há também o medo e a angústia dos familiares pela possibilidade de crise, por não poder deixar o paciente sozinho, pelo risco de sofrer agressões de toda natureza e ainda ter de enfrentar as perdas materiais. As modificações da rotina familiar acarretam sofrimento ao grupo, principalmente no período adaptativo ou após a alta hospitalar e remissão dos sintomas, devido à falta de preparo e orientação à assistência ao familiar doente.

Deve-se também considerar a codependência da família (Diehl, Silva \& Bosso, 2017) um transtorno emocional característico de pessoas que convivem constantemente com o usuário de álcool e outras drogas e desenvolvem um conjunto de pensamentos patológicos que se traduz em um intenso sofrimento psíquico. Diante da interferência da codependência na vida e no cumprimento das obrigações sociais, é indispensável oferecer assistência profissional no intuito de minimizar a sobrecarga e fortalecer os mecanismos protetores. A crise desencadeada pela recaída, pode favorecer um ambiente propício ao afeto negativo por parte do familiar que só aumenta a culpa do dependente químico e o consumo de álcool e outras drogas. O suporte as famílias pode ser realizado mediante oficinas e demais atividades grupais (Kalan et al, 2017) em que se observa progressivamente melhora na relação entre os membros. 
Igualmente são de grande importância os encontros ou consulta familiar que oportunizam a troca de experiências, a realização de técnicas de relaxamento e orientação junto as famílias das formas de acolhimento do individuo com transtorno mental. Estratégias, cujo potencial terapêutico e educativo melhoram a convivência e a harmonia no grupo, sendo imprescindível por apoiar os familiares e amenizar suas dificuldades e inseguranças.

Na visão da família (Felix Junior et al, 2015) a reinserção psicossocial do dependente químico através do trabalho é uma estratégia essencial em sua recuperação, pelo fato de o indivíduo exercer a sua autonomia, ter disciplina em termos de horários, rotinas e também desenvolver a sua criatividade e / ou habilidades que se encontravam encobertas devido ao consumo de drogas. Portanto, a família deve ser entendida como eixo primário das relações que possibilitam a efetividade do tratamento e acompanhamento do dependente químico e não mais como a causa ou agente que leva ao uso da droga. Há necessidade de ações que promovam o fortalecimento do núcleo familiar como fator protetor na prevenção e atenção a questão da dependência de álcool e outras drogas.

Sob este ponto de vista psicossocial, o trabalho (Fava, Silva \& Silva, 2015) é parte das ações preventivas relacionadas ao uso de drogas e direcionadas ao desenvolvimento humano e que possibilita o acesso à educação para a vida saudável, aos bens culturais, à prática de esportes, à cultura e ao lazer.

A socialização do conhecimento sobre drogas deve envolver a participação dos jovens através da escola, da família e da sociedade. O fato de estar casado e empregado ou estudar (Valentim, Santos, Ribeiro, 2015) são fatores protetores e promotores da resiliência familiar.

E com o passar do tempo, parece que os familiares vão se adaptando ao problema do alcoolismo e desenvolvem mecanismos adaptativos capazes de proporcionar o apoio necessário que sustentar os sentimentos de autoestima e autoconfiança dos seus membros.

Por outro lado, as pesquisas apontam (Amaral \& Bresser, 2015) a tendência de os profissionais de saúde mental, ainda enxergarem somente a pobreza, a impotência e a impossibilidade da família.

Tal posicionamento é um risco ou mesmo um equívoco, pois a família deve ser entendida como um grupo social capaz de reorganizar suas demandas e reconstruir vínculos ameaçados por meio do apoio dos serviços.
Ressalta-se que diante da insuficiência de políticas públicas materializadas em serviços, outros atores como as organizações não governamentais, igrejas, entidades filantrópicas, fundações entre outras, têm assumido o apoio e o fortalecimento da família, como parte da rede de atenção psicossocial de modo a promover a autonomia e harmonia dos seus integrantes.

\section{CONCLUSÃO}

As famílias que participaram do estudo, por conviverem diariamente com pessoas com histórico de consumo de bebidas alcoólicas e outras drogas, reconhecem e acreditam na importância do trabalho como estratégia de organização da vida social e da personalidade do indivíduo. No entanto, sofrem com as dificuldades de inserção do familiar no mundo do trabalho, devido às recaídas em que se evidenciaram sobrecargas emocional, social e financeira do grupo. Há necessidade de suporte às famílias por parte das instituições e profissionais de saúde mental com o intuito de promover o acolhimento e elaboração de estratégias que minimizem as sobrecargas relatadas. A participação do dependente químico em oficinas de trabalho e de geração de rendas nos serviços de saúde mental pode favorecer a autonomia, a criatividade e a credibilidade social com vistas à futura inserção em postos de trabalho e minimização do sofrimento do grupo.

\section{IMPLICAÇÕES PARA A PRÁTICA CLÍNICA}

O presente estudo poderá contribuir com as reflexões e discussões junto às instituições, gestores, profissionais de saúde mental e de outras áreas sobre a importância de se conhecer as dificuldades enfrentadas pela família no que diz respeito à inserção do dependente químico no mercado de trabalho.

Pelo próprio estigma da dependência química, essas pessoas são desacreditadas socialmente, sendo na maioria das vezes culpadas por não se manterem sóbrias.

Há o medo do desemprego por parte da família e do usuário e quando ocorre a demissão, as instituições que não possuem programas de acolhimento do dependente químico, costumam transferir o problema para o indivíduo e a própria família.

Neste contexto, as famílias se sentem sobrecarregadas e adoecem pelo fato de ter uma pessoa que não contribui com as despesas, como também se retraem socialmente em função do preconceito. 
Portanto, cabem aos profissionais de saúde mental e, dentre eles, o enfermeiro, desenvolver projetos e estratégias de acolhimento dos familiares, no intuito de fornecer informações no que dizem respeito à dependência química e propiciar um espaço de elaboração do sofrimento, de modo a minimizar as crises na família e o afeto negativo.

Deve-se incluir o dependente em atividades de produção de trabalho e de renda nas instituições como os CAPSad, propiciando assim a autonomia, a liberdade de expressão e a criatividade, fatores que podem diminuir as recaídas e as sobrecargas financeira, emocional e social da família.

\section{REFERÊNCIAS BIBLIOGRÁFICAS}

Amaral, D. A., \& Bressan, C. M. F. (2015). A centralidade da família nos serviços de atendimento de pacientes com transtornos mentais e dependentes químicos. Revista Serviço Social, 17(2),108-24. Disponível em: http://www.uel.br/revistas/uel/index.php/ssrevista/article/view/21807

Amarante P. (2013). Saúde Mental e Atenção Psicossocial. ( $4^{\text {a }}$ ed.). Rio de Janeiro: Fiocruz.

Bardin, L. (2011). Análise de conteúdo. ( $3^{\text {a }}$ ed.). Lisboa: Edições 70.

Bessa, J. B., \& Pagliarini, M. A. (2013). Família da pessoa com transtorno mental e suas necessidades na assistência psiquiátrica. Revista Texto \& Contexto Enfermagem, 22(1), 61-70. Doi: 10.1590/S0104-07072013000100008

Diehl, A.; Silva, D., \& Bosso A.T. (2017). Codependência entre famílias de usuários de álcool e outras drogas: de fato uma doença? Revista Debates em Psiquiatria, 7(1), 34-42. Disponível em: https://www.bairral.com. br/blog/bastidores/codependencia-entre-familias-deusarios-de-alcool-e-outras-drogas-de-fato-uma-doen$\mathrm{ca} /$

Fava, M., Silva, N. R., \& Silva, M. L. (2015). Avaliação da sobrecarga em cuidadores familiares de pacientes de um centro de atenção psicossocial. Barbarói. Revista do Departamento de Ciências Humanas, 2(41), 41-55. Disponível em: https://online.unisc.br/seer/index.php/ barbaroi/article/view/4690
Felix Junior, I. J., Schlindwein, V. L. D. C., \& Calheiros, P. R. V. (2016). A relação entre o uso de drogas e o trabalho: uma revisão de literatura. Estudos e Pesquisas em Psicologia, 16(1), 104-122. Disponível em: http:// pepsic.bvsalud.org/scielo.php?script=sci_arttext\&pid $=$ S1808-42812016000100007

Kalam, A. F. A., Carbogim, F. C., Barbosa, A. C. S., Luiz, F. S., Paula, C. F., \& Santos, A. S. P. (2017). Demandas dos familiares de pessoas com transtorno mental. Revista Enfermagem da Universidade Federal do Piauí, 6(3),11-17. Disponível em: http://www.ojs.ufpi.br/index.php/reufpi/article/view/6204

Lima, C. B., Brêda, M. Z., \& Albuquerque, M. C. S. (2013). Acolhimento ao familiar da pessoa em sofrimento psíquico nos estudos de enfermagem. Revista Brasileira de Promoção da Saude, 26(4), 571-580. Doi: 10.5020/18061230.2013.

Minayo, M. C. S. (2013). O desafio do conhecimento: pesquisa qualitativa em saúde. (13 ${ }^{a}$. ed.). São Paulo: Hucitec.

Ministério da Saúde. (2011). Legislação e Políticas sobre Drogas no Brasil. Secretaria Nacional de Políticas sobre Drogas. Brasília: Editora (MS).

Salles, M. M.; \& Barros, S. (2013). Exclusão/inclusão social de usuários de um centro de atenção psicossocial na vida cotidiana. Revista Texto \& Contexto Enfermagem, 22(3),704-712. Disponível em:http://www.scielo.br/scielo.php?pid=S0104-07072013000300017\&script $=$ sci_ abstract\&tlng=pt

Saraceno, B. A. (2001). Libertando identidades: Da reabilitação psicossocial à cidadania possível. Rio de Janeiro: Te Corá/Instituto Franco Basglia.

Schein, S., \& Boeckel, M. G. (2012). Análise da sobrecarga familiar no cuidado de um membro com transtorno mental. Saúde \& Transformação Social, 3(2), 3242. Disponível em: http://incubadora.periodicos.ufsc. br/index.php/saudeetransformacao/article/view/1474 
Valentim, O. M. M. S, Santos, C. S. V. B, Ribeiro, J. L. P. (2015). Vulnerability to stress and quality of life in relatives of people with alcoholism. Revista Portuguesa de Enfermagem de Saúde Mental, (spe2),57-62. Disponível em: http://www.scielo.mec.pt/pdf/rpesm/ nspe2/nspe2a10.pdf
Volz, P. M., Tomasi, E.; Bruck, N. R. V.; Saes, M. O.; Nunes, B. P.; Duro, S. M. S.; \& Facchin, L. A. (2015). A inclusão social pelo trabalho no processo de minimização do estigma social pela doença. Revista Saúde Sociedade, 24(3), 877-886. Doi: 10.1590/S010412902015130040

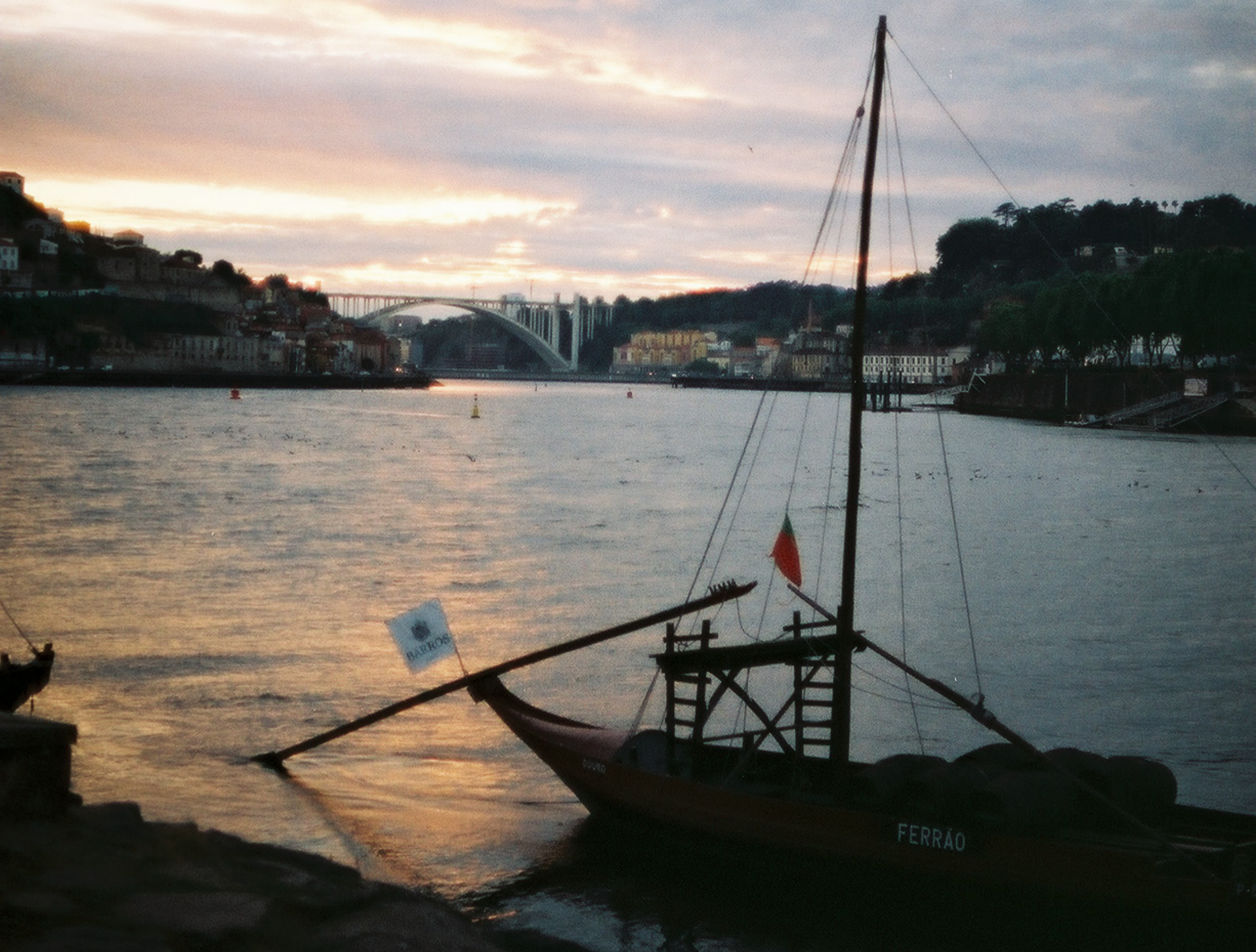

